\title{
Lymphoepithelial carcinoma: a case report of a rare tumor of the larynx
}

\author{
Nawal Hammas ${ }^{1,2^{*}}$ (D), Najib Benmansour ${ }^{3}$, Mohamed Nour-dine El Alami El Amine ${ }^{3}$, Laila Chbani ${ }^{1,2}$ \\ and Hind El Fatemi ${ }^{1,2}$
}

\begin{abstract}
Background: Lymphoepithelial carcinoma is a tumor mostly diagnosed in the nasopharynx, but it has also been described in a variety of nonnasopharyngeal sites. It is extremely rare in the larynx and should be distinguished from squamous cell carcinoma. Therefore, it must be known by clinicians, pathologists and oncologists. In this case report, we discuss its etiopathogeny, its epidemiological, clinical, pathological and therapeutic aspects, and its outcome.
\end{abstract}

Case presentation: An 81-year-old Morrocan man, smoker for 40 years, presented with a 1 year history of dysphonia, dyspnea and dysphagia. Laryngoscopy showed a mass occupying supraglottic, glottic and subglottic levels of the larynx. Cervico-thoracic computed tomography scan showed a laryngeal wall thickening with cervical lymphadenopathy. Laryngeal biopsy was performed. Microscopic analysis and immunohistochemistry confirmed the diagnosis of laryngeal lymphoepithelial carcinoma. Immunostaining for LMP1 was negative.

Conclusion: Laryngeal lymphoepithelial carcinoma is an extremely rare and an aggressive tumor. It is rarely associated with the EBV. It must be regarded as a distinct entity. Radiotherapy is advisable as the unique therapy for local tumor. A correct diagnosis and a close collaboration between the pathologist and clinicians is mandatory for an optimal treatment strategy.

Keywords: Larynx, Lymphoepithelial carcinoma, Epstein- Barr virus

\section{Background}

Lymphoepithelial carcinoma (LEC) is a neoplasm mostly located in the nasopharynx where it represents $40 \%$ of all neoplasms $[1,2]$. It occurs worldwide but it has an endemic geographic distribution, particularly in Southeast Asia and Eskimos [3]. Nonnasopharyngeal LEC has also been reported in other locations, such as sinonasal tract, nasolacrimal duct, oral cavity, oropharynx, salivary glands, thymus, hypopharynx, esophagus, stomach, trachea, lung, and others [1-4]. Many terms have been used for nonnasopharyngeal LEC like undifferentiated carcinoma of nasopharyngeal type, undifferentiated carcinoma with lymphoid stroma, lymphoepithelioma, lymphoepithelial-like carcinoma and lymphoepithelial carcinoma. The latter has been approved by the World Health Organization [5]. Nonnasopharyngeal and nasopharyngeal LEC have the same microscopic appearance

\footnotetext{
* Correspondence: nawalhammas@gmail.com

${ }^{1}$ Department of Pathology, Hassan II University Hospital, 30000 Fez, Morocco

${ }^{2}$ Biomedical and Translational Research Laboratory, Faculty of Medicine and

Pharmacy, Sidi Mohamed Ben Abdellah University, Fez, Morocco

Full list of author information is available at the end of the article
}

but their relationship to EBV is different. In fact, the former is less likely associated to EBV $[2,3]$.

LEC is extremely rare in the larynx [4]. We present herein one new laryngeal presentation and, through this case, we discuss the clinical and histopathologic findings, the diagnosis problems and therapeutic aspects of this rare neoplasm.

\section{Case presentation}

An 81-year-old Morrocan man, smoker for 40 years, presented with a 1 year history of dysphonia, dyspnea and dysphagia. Laryngoscopy showed a mass occupying supraglottic, glottic and subglottic levels of the larynx, with extension to the epiglottis, the tongue base and the retro-cricoid area. Cervico-thoracic computed tomography scan showed a laryngeal wall thickening especially at the glottic and supraglottic levels with cervical lymphadenopathy without distant metastasis. Laryngeal biopsy was performed and revealed, on microscopic examination, a malignant tumor composed of solid sheets disposed in lymphoid background (Fig. 1). Tumor cells 


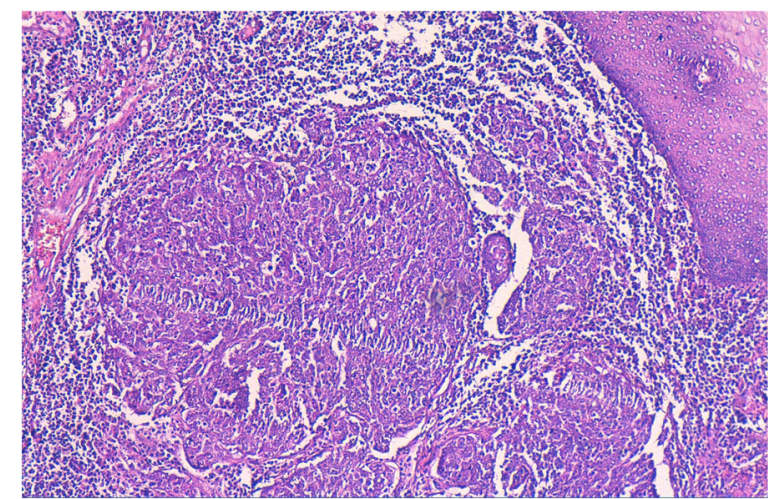

Fig. 1 Microscopic appearance: the tumor is composed of compact nests and sheets of epithelial cells surrounded by a prominent component of mature lymphocytes and plasma cells. Hematoxylin and eosin stain; original magnification $\times 100$

were round, large, poorly differentiated, nonkeratinized, and contained large round vesicular nuclei with prominent nucleoli. The cytoplasm was poorly limited (Fig. 2). Surface epithelium exhibits some alterations like hyperplasie and keratosis, without dysplasia. Automated immunohistochemistry showed positivity for Cytokeratin 5/6 (D5/16B4) (Fig. 3). Neuroendocrine markers (chromogranin and synaptophysin), melanoma markers (Melan A and HMB45), myogenic markers (desmin and smooth muscle actin), LCA (leucocyt commun antigen), CD99 and CD117 were negative. These histological and immunohistochemical results confirmed the diagnosis of laryngeal lymphoepithelial carcinoma. Screening for EBV by immunohistochemistry using anti-LMP 1 antibody (latent membrane protein 1) was negative. The patient underwent tracheotomy and radiotherapy.

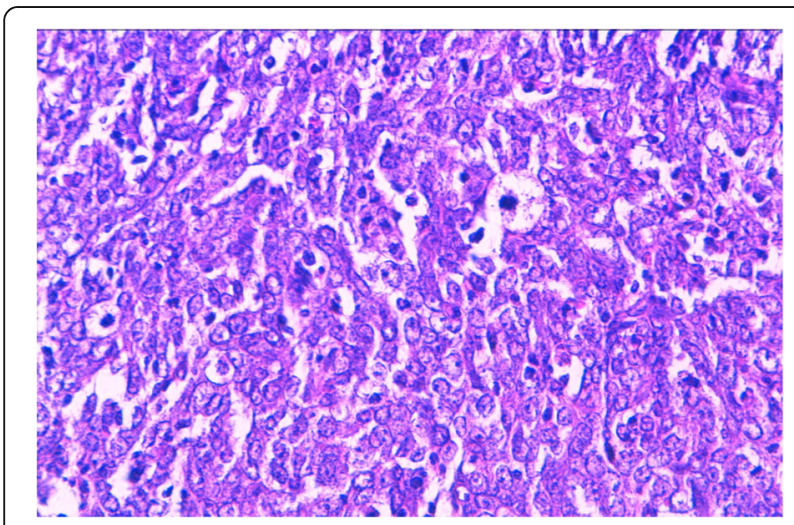

Fig. 2 Microscopic appearance: tumor cells are undifferentiated, large, with round, vesicular nuclei, containing a prominent nucleolus, and with an abundant, ill defined cytoplasm. Hematoxylin and eosin stain; original magnification $\times 400$

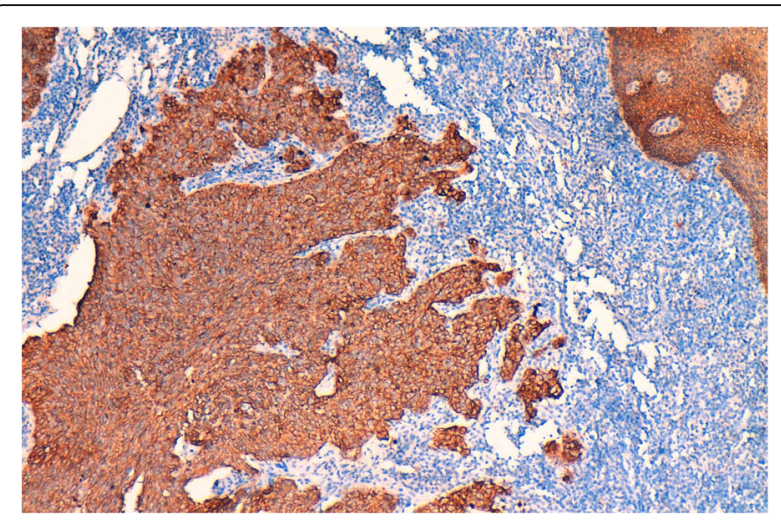

Fig. 3 positive immunohistochemical staining for cytokeratin 5/6

\section{Discussion}

LEC of the larynx is an extremely rare and aggressive tumor which accounts for $0.2 \%$ of all laryngeal cancers $[2,4,6]$. It most commonly originates from supraglottic region, usually centered around the ventricles or involving the epiglottis $[2,3,6]$. It occurs mostly in older adults (mean 62 years) with male predominance (male/female ratio $=3: 1$ [ [3]. The main symptom is dysphagia or hoarseness [7]. In our case, the tumor was occupying all larynx and was accompanied by cervical lymphadenopathy.

Macroscopically, the tumor forms a mass that may be ulcerated [5]. Diagnosis can be challenging because the tumor may arise from hidden, submucosal sites. Microscopically, laryngeal LEC is similar to the nasopharyngeal one. It comprises solid sheets or irregular islands of malignant epithelial cells intimately intermingled with prominent component of lymphocytes and plasma cells [2-4]. Tumor cells are large, with indistinct cell borders, round to oval vesicular nuclei, and a single large central nucleoli [3]. A component of squamous cell carcinoma accounting for $10-75 \%$ of the tumour may be seen in about half of the cases. This component was not found in our case. The overlying epithelium can show carcinoma-in-situ [5]. Immunohistochemically, tumor cells show positive staining for keratin and epithelial membrane antigen [2]. In the present case, immunohistochemical stains for cytokeratin was positive and constituted a proof of epithelial differentiation.

Distinction between LEC on the one hand and large cell lymphoma and melanoma on the other hand is pronostically important and can at times be difficult. Immunohistochemistry is essential in differential diagnosis by demonstrating expression of cytokeratin in LEC. Immunostaining with melanocyte differentiation markers (HMB45 or Melan-A) and lymphoid markers is useful to eliminate melanoma and lymphoma respectively. Nasopharyngeal carcinoma with laryngeal metastasis must also be eliminated $[5,8,9]$. 
The relationship between EBV and LEC of the larynx remains controversial. Laryngeal LEC is less likely associated with EBV than its nasopharyngeal conterpart $[2,6]$. MacMillan et al. [3] studied eight cases of LEC of the larynx and hypopharynx. They found that none of the cases was positive for EBV and suggested that the EBV has a limited role in the etiopathogenesis of this tumor in patients of non-Asian descent. The same conclusion was proposed by Marioni et al. [10] who found, among 16 cases evaluated for the presence of EBV, only four cases $(25 \%)$ positive for this virus. In our case, immunostaining for EBV was negative.

In order to evaluate the modes of invasion of laryngeal and pharyngeal carcinomas, Micheau et al. [11] studied 2430 laryngectomy and pharyngolaryngectomy surgical specimens. They found a single or double laryngocele in $70 \%$ of the cases. Histolologic analysis of the laryngoceles showed cylindrical or squamous epithelium with organized lymphoid tissue, similar of the histology of lymph nodes and lymphoid structures of Waldeyer's ring. This lymphoid-lined structure is probably the site of origin of laryngeal LEC. Alternatively, Toker and Peterson [12] postulated that the site of origine of these lesions may be active basal epithelium of the larynx, which is similar to epithelium of tonsillar crypts. Relationship between LEC and smoking is different in laryngeal and nasopharyngeal location. In the former, smoking may play a role while in the latter, it is not considered to be a risk factor $[1,4]$. In our case, the patient had a long history of smoking.

Laryngeal LEC is a highly radiosensitive disease and radiotherapy should be considered as the main treatment because it provides excellent local control rates [2, $4,6]$. The value of chemotherapy is still unknown. Neoadjuvant chemotherapy may be recommanded in cases of early regional adenopathy with the aim of decreasing the distant metastasis rate $[4,6]$.

Laryngeal LEC shares many characteristics with its nasopharyngeal counterpart. They both have significant susceptibility for early regional and distant metastases. The initial stage is the primary determinant of prognosis. Death from disease occurs in about one third of patients. $[3,4,13]$.

\section{Conclusion}

LEC of the larynx is an extremely rare and an aggressive tumor. It has the same microscopic features as its nasopharyngeal counterpart. Radiotherapy is advisable as the unique therapy for local tumor. A correct diagnosis and a close collaboration between the pathologist and clinicians is mandatory for an optimal treatment strategy.

\section{Abbreviations}

EBV: Epstein-Barr Virus; LEC: Lymphoepithelial carcinoma; LMP 1: Latent membrane protein 1
Acknowledgements

Not applicable.

Funding

The authors received no specific funding for this study.

\section{Availability of data and materials}

All data generated or analysed during this study are included in this published article.

\section{Authors' contributions}

$\mathrm{NH}, \mathrm{LC}$ and HE performed the histological examination of the tumor and were major contributors to writing the manuscript. NB and MNE analyzed and interpreted the patient data and performed biopsy. All authors read and approved the final version of the manuscript.

\section{Ethics approval and consent to participate}

Not applicable.

\section{Consent for publication}

Written informed consent was obtained from the patient for publication of this case report and any accompanying images. A copy of the written consent is available for review by the editor of this journal.

\section{Competing interests}

The authors declare that they have no competing interests.

\section{Publisher's Note}

Springer Nature remains neutral with regard to jurisdictional claims in published maps and institutional affiliations.

\section{Author details \\ ${ }^{1}$ Department of Pathology, Hassan II University Hospital, 30000 Fez, Morocco. ${ }^{2}$ Biomedical and Translational Research Laboratory, Faculty of Medicine and Pharmacy, Sidi Mohamed Ben Abdellah University, Fez, Morocco. \\ ${ }^{3}$ Department of otorhinolaryngology, HASSAN II University Hospital, Faculty of Medicine and Pharmacy, Sidi Mohammed Ben Abdellah University, Fez, Morocco.}

Received: 24 April 2017 Accepted: 9 November 2017

Published online: 25 November 2017

\section{References}

1. Andryk J, Freije JE, Schultz CJ, Campbell BH, Komorowski RA. Lymphoepithelioma of the larynx. Am J Otolaryngol. 1996;17(1):61-3.

2. Coskun BU, Cinar U, Sener BM, Dadas B. Lymphoepithelial carcinoma of the larynx. Auris Nasus Larynx. 2005:32:189-93.

3. Macmillan CA, Kapadia SB, Finkelswtein SD, Nalesnik MA, Barnes L. Lymphoepithelial carcinoma of the larynx and hypopharynx: study of eight cases with relationship to Epstein-Barr Virus and p53 gene alterations, and review of the literature. Hum Pathol. 1996;27(11):1172-9.

4. Bansal S, Shankar A, Gupta AK. Undifferentiated carcinoma of larynx of nasopharyngeal type. Online J Health Allied Sci. 2011;10(1):1-2.

5. El-Naggar AK, Chan JKC, Grandis JR, Takata T, Slootweg PJ. World Health Organization classification of head and neck tumours, WHO/IARC classification of tumours, vol. 9. 4th ed; 2017.

6. Ibrahimov M, Yilmaz M, Celal MH, Mamanov M, Yollu U, Ozek H. Lymphoepithelial carcinoma of the larynx. J Craniofac Surg. 2013;24(3):1049.

7. Sone M, Nakashima T, Nagasaka T, Itoh A, Yanagita N. Lymphoepitheliomalike carcinoma of the larynx associated with an Epstein-Barr viral infection. Otolaryngol Head Neck Surg. 1998;119(1):134-7.

8. Hayashi T, Haba R, Tanizawa J, Katsuki N, Kadota K, Miyai Y, Bando K, Shibuya S, Nakano M, Kushida Y. Cytopathologic features and differential diagnostic considerations of primary lymphoepithelioma-like carcinoma of the lung. Diagn Cytopathol. 2012;40(9):820-5.

9. Kermani W, Belcadhi M, Sriha B, Abdelkéfi M. Epstein-Barr virus-associated lymphoepithelial carcinoma of the larynx. Eur Ann Otorhinolaryngol Head Neck Dis. 2015;132:231-3.

10. Marioni G, Mariuzzi L, Gaio E, Portaleone S, Pertoldi B, Staffieri A. Lymphoepithelial carcinoma of the larynx. Acta Otolaryngol. 2002;122:429-34. 
11. Micheau C, Luboinski B, Schwaab G, Richard J, Cachin Y. Lymphoepitheliomas of the larynx (undifferentiated carcinomas of nasopharyngeal type). Clin Otolaryngol. 1979;4:43-8.

12. Toker C, Peterson DW. Lymphoepithelioma of the vocal cord. Arch Otolaryngol. 1978 Mar;104(3):161-2.

13. Ferlito A, Weiss LM, Rinaldo A, Carbone A, Devaney KO, MacMillan C, Barnes L. Clinicopathological consultation. Lymphoepithelial carcinoma of the larynx hypopharynx, and trachea. Ann Otol Rhinol Laryngol. 1997;106(5):437-44.

Submit your next manuscript to BioMed Central and we will help you at every step:

- We accept pre-submission inquiries

- Our selector tool helps you to find the most relevant journal

- We provide round the clock customer support

- Convenient online submission

- Thorough peer review

- Inclusion in PubMed and all major indexing services

- Maximum visibility for your research

Submit your manuscript at www.biomedcentral.com/submit 